\title{
IDENTIFIKASI JAMUR Candida albicans PADA AIR BAK TOILET UMUM DI PASAR TRADISIONAL KOTA PEKANBARU
}

\section{Siti Juariah, Nabila Maritza}

Faculty of Faculty of Medicine and Health Sciences, Universitas Abdurrab, Indonesia sitijuariah@univrab.ac.id

\begin{abstract}
The market is a forum for meetings between sellers and buyers to transact directly, while traditional is interpreted as an attitude and way of thinking and acting that always cling to norms and customs. The market can be a pathway for the spread of disease. The existence of sanitation facilities is very important to provide flexibility to traders and visitors who are active in the market, for example, toilets. The purpose of this study was to determine whether or not there is Candida albicans fungus in toilet tub water in the traditional market of Pekanbaru city. This research was conducted using the Experimental method. Based on the results of an examination of 8 markets in the city of Pekanbaru, there were 5 markets that were found to be positively contaminated with fungi Candida albicans, and 3 other markets contaminated with fungi of other species. Conclusion that of the 15 samples of toilet tub water in the traditional market of Pekanbaru city were found 8 samples contaminated with albicans candida fungi
\end{abstract}

Key words: Traditional Market; Toilet; Candida albicans

\begin{abstract}
Abstrak Pasar merupakan sebuah wadah pertemuan antara penjual dan pembeli untuk bertransaksi secara langsung, sedangkan tradisional dimaknai sebagai sikap dan cara berpikir serta bertindak yang selalu berpegang teguh kepada norma dan adat. Pasar bisa menjadi jalur penyebaran penyakit. Keberadaan fasilitas sanitasi sangat penting untuk memberikan keleluasaan pada pedagang dan pengunjung yang beraktivitas di pasar tersebut, contohnya seperti toilet. Tujuan dari penelitian ini untuk mengetahui ada atau tidaknya jamur Candida albicans pada air bak toilet di pasar tradisional kota Pekanbaru. Penelitian ini dilakukan dengan menggunakan metode Experimental. Berdasarkan hasil pemeriksaan dari 8 pasar yang ada dikota Pekanbaru, ada 5 pasar yang ditemukan positif terkontaminasi jamur Candida albicans, dan 3 pasar lainnya terkontaminasi jamur spesies lain. Kesimpulan bahwa dari 15 sampel air bak toilet yang ada di pasar tradisional kota Pekanbaru ditemukan 8 sampel yang terkontaminasi jamur candida albicans .
\end{abstract}

Kata kunci : Pasar Tradisional; Toilet; Candida albicans

\section{Pendahulan}

Pasar tradisional merupakan salah satu tempat untuk manusia berbelanja memenuhi kebutuhan bahan pangan dan. Pasar bisa menjadi jalur penyebaran penyakit. Peran pasar sehat diperlukan dalam mewujudkan kabupaten / kota sehat. Keberadaan fasilitas sanitasi sangat penting untuk memberikan keleluasaan pada pedagang dan pengunjung yang beraktivitas di pasar tersebut, contohnya seperti toilet sandang (Anggraini, dkk 2017). Toilet adalah sarana sanitasi yang paling vital dan kebersihan toilet dapat dijadikan ukuran terhadap kualitas manajemen sanitasi di suatu tempat. Parameter kebersihan toilet yang paling utama dapat dilihat dari frekuensi menguras atau pembersihan bak airnya. Sanitasi yang kurang baik dapat menyebabkan air bak toilet ditumbuhi oleh jamur. Air yang terkontaminasi oleh jamur Candida albicans jika digunakan untuk membersihkan diri, maka dapatmenyebabkan kandidiasis vagina, kandidiasis kulit dan kandidiasis kuku (Hendlyana, dkk 2012)

Kontaminasi Candida sp pada air bak toilet bisa berasal dari telapak tangan dan kuku jari pengguna toilet yang mencuci tangan setelah melakukan defekasi. Selain itu hiegene dan sanitasi toilet umum yang tidak dijaga dengan baik merupakan faktor utama yang sangat mempengaruhi pertumbuhan dan jumlah 
Candida sp pada air bak toilet (Prahatamaputra, 2009) Penelitian yang dilakukan oleh Virgianti\& Nurwaniansah, (2014) menyatakan bahwa pada air kolam renang ditemukan jamur Candida albicans sebanyak 20\%, Candida krusei $10 \%$, Candida parapsilosis $10 \%$, serta $60 \%$ jamur yang tidak teridentifikasi. Qurrohman \&Nugroho,(2015) menambahkan bahwa ada pengaruh frekuensi menguras terhadap jumlah jamur Candida. sp pada air bak toilet wanita di SPBU wilayah Surakarta. penelitian ini dimaksudkan untuk melihat Apakah terdapat jamur Candida albicans pada sampel air bak toilet di pasar tradisional kota Pekanbaru. Penelitian ini bertujuan Mengidentifikasi adanya Candida albicans pada air bak toilet umum di pasar tradisional kota Pekanbaru.

\section{Metode Penelitian}

Penelitian ini dilakukan dengan menggunakan metode Experimental. Alat yang digunakan yaitu oven, timbangan analitik, cawan petri, autoklaf, bunsen, inkubator, erlemeyer $500 \mathrm{~mL}$, gelas ukur $100 \mathrm{~mL}$, korek api, tisu, label, kertas padi, mikroskop, objek glas, deck glas, spuit, ose cincin dan jarum, dan selotip.

Bahan yang digunakan yaitu imersi oil, larutan LPCB (lactho phenol catton blue), alkohol $70 \%$. Media yang digunakan yaitu PDA (Potato Dextrose Agar).

\section{Pengambilan sampel air}

Pengambilan sampel air dilakukan pada air bak toilet di pasar tradisional kota Pekanbaru. Sampel air diambil dengan cara mengaduk air terlebih dahulu hingga tercampur rata dengan menggunakan gayung. Air kemudian diambil dan dimasukkan ke dalam botol sampel steril.

\section{Pembuatan media PDA}

Potato Dextrose Agar (PDA) ditimbang sebanyak 19,5 g, dimasukkan kedalam labu erlenmeyer, lalu dilarutkan dalam $500 \mathrm{~mL}$ akuades, didihkan. Kemudian media ditutup dengan kapas steril, lalu disterilkan dalam autoklaf selama 1 jam pada suhu $121^{\circ} \mathrm{C}$. Setelah proses sterilisasi selesai, media dikeluarkan dari autoklaf, dinginkan hingga suhu 45 - 50 C. tambahkan antibiotic klorampenicol kadar 500mg sebanyak $5 \mathrm{~mL}$ aquadess untuk menghambat pertumbuhan bakteri (Oxoid, 2015)

\section{Inokulasi dan inkubasi sampel}

Pipet $1 \mathrm{~mL}$ sampel air masukkan ke dalam cawan petri kosong yang sudah di sterilkan, tuangkan media PDA yang masih cair ke cawan petri sebanyak 15 - $20 \mathrm{~mL}$ dengan menggunakan metode pour plate, kemudian putar cawan untuk menghomogenkan sampel dengan media, lalu dilakukan pengulangan sebanyak 3 kali. Inkubasi media yang telah dilakukan penanaman pada suhu 37 C selama 48 jam (Sukenti, 2015)

\section{Jaminan kualitas sampel}

Jaminan kualitas sampel dilakukan supaya menjamin tidak ada kontaminasi yang berasal dari luar (variabel perancu) dengan kontrol negatif. Kontrol negatif merupakan media PDA yang tidak digunakan inokulasi sampel air, namun juga diperlakukan seperti media dengan sampel. Kontrol ini digunakan untuk menjamin bahwa sampel tidak terkontaminasi saat melakukan percobaan

\section{Identifikasi koloni pada media PDA.}

Identifikasi koloni dilakukan secara makroskopis dan mikroskopis. Koloni yang tumbuh pada media PDA yang telah diinkubasi selama 48 jam pada suhu $37 \mathrm{C}$, diamati secara makroskopis Karakteristik spora dan hifa jamur diamati dengan mikroskop perbesaran 100× (obyektif 10×). Jumlah koloni Candida albicans yang tumbuh pada media PDA dihitung secara keseluruhan dan dinyatakan dalam koloni / $\mathrm{mL}$ sampel. 
JOPS (Journal Of Pharmacy and Science)

Vol 3 No 1 Desember 2019

\section{Hasil dan Pembahasan}

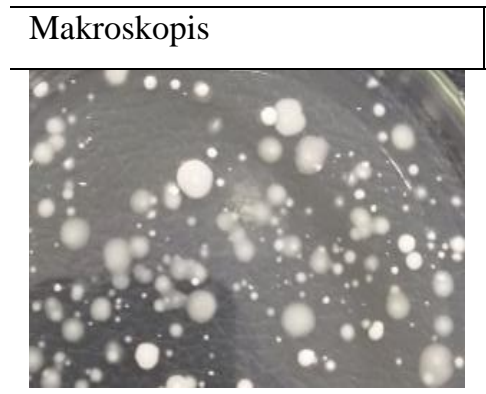

koloni berukuran kecil, berbentuk bulat, berwarnakrem, berbau ragi, dengan tepian yang halus dan rata

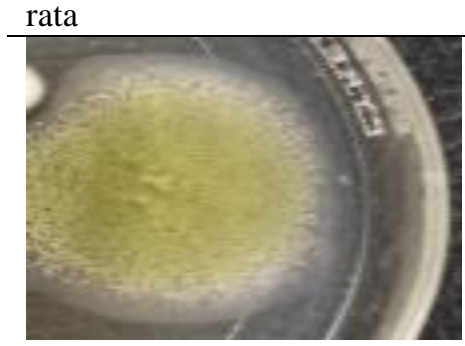

Koloni berbentuk filamen berwarna hijau tua atau hitam dengan tepian berwarna putih

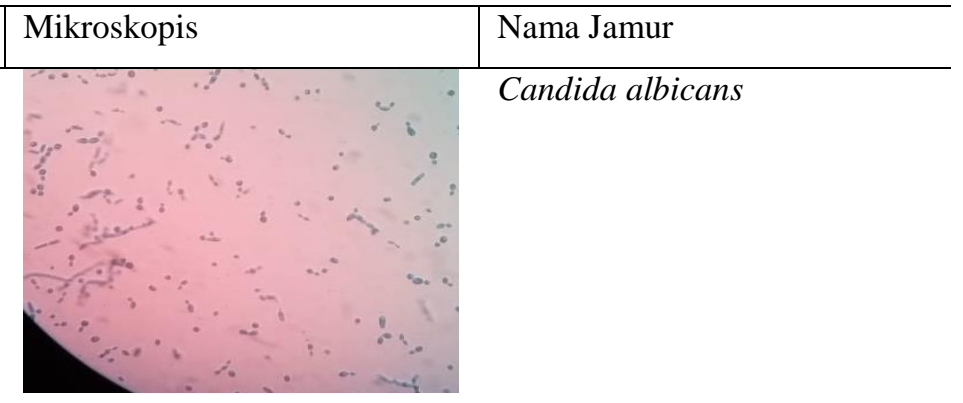

Koloni oval, memiliki

pseudohifa, dan blastospora

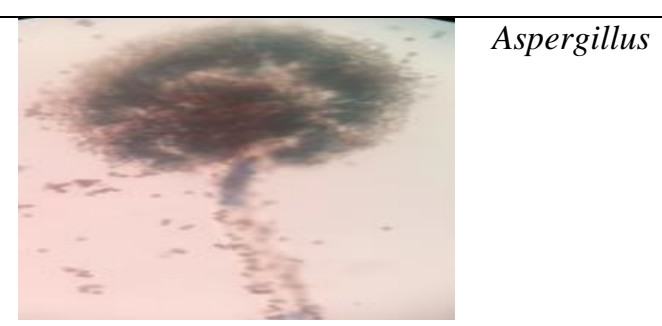

Konidia atas berwarna hitam kecoklatan, terdapat pesikel dan sterikmata

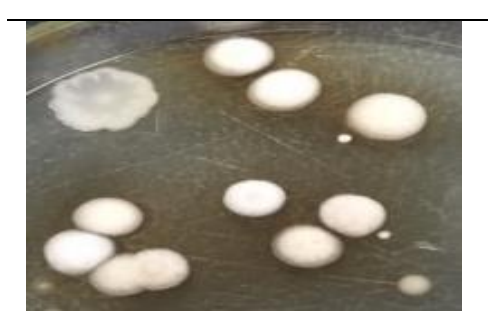

Koloni berwarna putih dengan tepian berwarna maroon

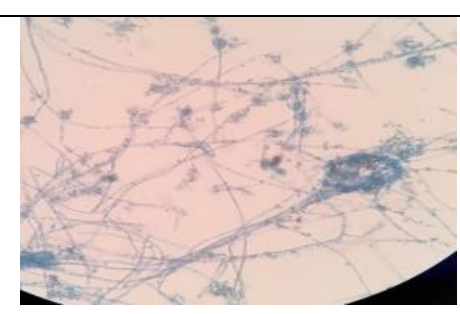

Terdapat hifa dan mikrokonidia

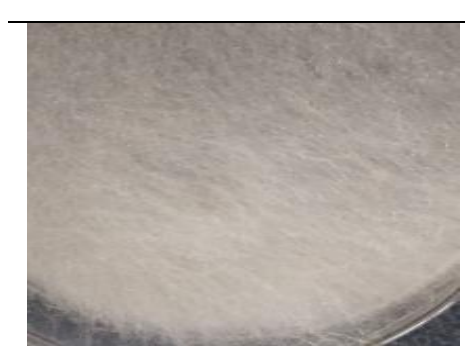

Koloni berwarna putih dengan tepian berwarna maroon

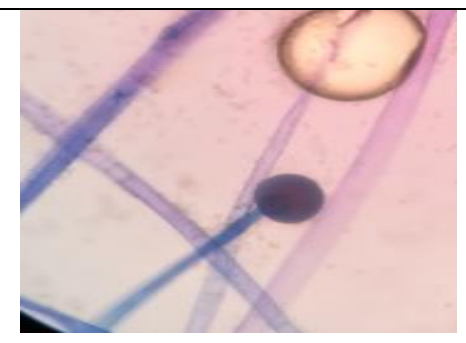

Mucor

Konidia berbentuk bulat, konidiafora tidak bercabang dan berdinding tipis

Sumber. Data primer

Gambar 1. Hasil Pemeriksaan pada Air Bak Toilet Di Pasar Tradisional Kota Pekanbaru 


\section{Kesimpulan}

Berdasarkan penelitian tentang identifikasi jamur Candida albicans pada air bak toilet umum di pasar tradisional kota Pekanbaru yang berjumlah 15 sampel, ada 8 sampel yang positif terkontaminasi jamur candida albicans dan ditemukan jamur spesies lain seperti Aspergillus, Trichopython dan Mucor. Beberapa faktor yang dapat mempengaruhi pertumbuhan jamur Candida albicans pada nutrien agar diantaranya adalah kontaminasi pada air. Kontaminasi jamur Candida albicans pada air bak toilet dapat disebabkan dari berbagai sumber, diantaranya adalah kontaminasi dari sumber air, kontaminasi dari pengunjung, dan lingkungan sekitar toilet. Frekuensi menguras berpengaruh secara langsung terhadap akumulasi jumlah jamur Candida albicans pada air bak toilet, karena pengurasan akan mempengaruhi kebersihan serta kualitas air dalam bak yang mempengaruhi pertumbuhan dari jamur Candida albicans. Selain itu, pengurasan akan membuat air dalam bak senantiasa di perbaharui sehingga memperkecil kontaminasi oleh mikroorganisme. Hal ini sesuai dengan penelitian sebelumnya yang menyatakan bahwa air yang mengalir mempunyai presentase lebih kecil untuk terkontaminasi oleh jamur Candida albicans (prahtamaputra, 2009).

\section{Ucapan Terima Kasih}

Ucapan terimakasih kepada Universitas Abdurrab yang telah menyediakan fasilitas penelitian serta rekan-rekan yang telah membantu penyelesaian penelitian ini.

\section{Referensi}

Agustina E, Marlinae L, dan Pujianti N. 2012 Gambaran Candida sp. Pada Air Bak Mandi Di Ruang Bersalin Rumah Sakit Umum daerah (RSUD) Banjar Baru. Jurnal Riset Kesehatan Masyarakat. Universitas Lambung Mangkurat

Anggraini, G., Amalia, D., dan Ismiyati, D. 2017. Konferensi Nasional Teknik Sipil 11 standarisasi penataan pasar tradisional di indonesia (studi kasus revitalisasi pasar di kota semarang), (November), 26-27.

Annaisse, E. J 2007 The Changging Epidemiology Of Candida Infection. 2-6 Cappucino, J. G., dan Sherma, N. 2014. Manual Laboratorium Mikrobiologi.

EGC. Jakarta

Dwipayanti U. 2008. Ketersediaan dan Pengelolaan Toilet di Tempat Wisata Pulau Bali. Makalah disajikan pada Seminar Nasional Kesehatan Pariwisata Untuk Meningkatkan Kualitas Pariwisata Dalam Rangka Visit Indonesia Year 2008. Denpasar, Bali. 24 Maret 2008.

Ganda, Husada S. 2000. Parasitologi Kedokteran. FKUI. Jakarta

Hendlyana, Y., Naria, E., dan Hasan, W. 2012. Pengelolaan Sanitasi Toilet Umum Dan Analisa Kandungan Candida albicans Pada Air Bak Toilet Umum di Beberapa Pasar Tradisional Kota Medan Tahun 2012, 1 8.

Prahatamaputra A. 2008. Karakteristik Jamur Candida albicans Berbasis Fermentasi Karbohidrat Pada Air Bak WC Sekolah Menengah di Kelurahan Alalak Utara. Jurnal Wahana-Bio. Vol 2: 1-13.

Qurrohman, M. T., dan Nugroho, R. W. 2015. Pengaruh Frekuensi Menguras Terhadap Jumlah Candida sp. Pada Air Bak Toilet Wanita di SPBU Surakarta. Biogenesis, 3(1).

Sukenti, E. 2015. Memanfaatkan Bakteri. Remaja Rosdakarya. Bandung 